\title{
UM CASO DE ALBINISMO EM TAYASSU TAJACU LINNAEUS (ARTIODACTYLA, TAYASSUIDAE) NA SERRA DO MAR, SÃO JOSÉ DOS PINHAIS, PARANÁ
}

\author{
L. A. Veiga ${ }^{1}$
}

\begin{abstract}
A CASE OF albinisM IN TAYASSU TAJACU LINNAEUS (ARTIODACTYl.A, Tayassuidae) in Serra do Mar. São José pos Pinhais, Paraná. Described herein is a case of albinism in the Peccary Tayassu tajacu Linnaeus, 1758 (Artiodactyla. Tayassuidae), which was observed in Colônia Castelhanos. São José dos Pinhais. Paraná, in the Southern Brazil. The specimen was captured when very young. The normal peccary (Tayassu tajacu) is a dark-gray animal with a white band across the chest from shoulder to shoulder. This animal have white skin, blued eyes but has pigmented feet.
\end{abstract}

KEY WORDS. Artiodactyla. Tayassuidae, Peccary, Toyyssu tajacu, albinism

Levando em consideração o caráter recessivo do albinismo tanto no homem como em outra espécie de animal, um indivíduo albino pode ser cruzado com um normal, sem que haja produção de filhos albinos (W ALTER 1938). Entretanto, os filhos de tal cruzamento podem gerar heterozigotos, cujos produtos têm possibilidade de serem portadores desta anormalidade de fundo genético relacionado a um defeito metabólico, onde um dos passos da síntese de melanina está hloqueado (HARRIS 1962; LERNER \& FITZPATRICK 1950; KARLSON et al. 1982; MAYS 1981; VEIGA \& PARDO 1990).

Segundo WaLTER (1938), um em cada vinte mil indivíduos pode apresentar algum tipo de albinismo. Pelo menos três gens podem ser responsabilizados por tal defeito metabólico e todos são recessivos. Um hloqueia a síntese de melanina exclusivamente nos olhos, é denominado alhinismo ocular e está localizado no cromossoma X, ligado ao sexo. Os outros dois bloqueiam a produção de melanina na pele, pêlos ou penas e olhos, causando o albinismo óculo-cutâneo. Não estão ligados ao sexo e ambos são autossomais (CAVALLI-SFORZA \& BODNER 1971; BEADLE 1945; FALLS 1953).

Nas matas que contornam a baia de Paranaguá, Paraná (Mata Atlântica) foi observado um exemplar albino de veado mateiro (Mazama americana Erxleben. 1777) (Rovedo, com.pes.). Em uma de suas viagens ao Pantanal. o autor observou, com auxílio de hınóculos, um indivíduo alhino tazendo parte de uma manada de veados campeiros (Ozotoceros hezoarticus Linnaeus, 1758). Era um exemplar já com a galhada crescida, mas ainda coberta de pele. A manada fugiu durante a aproximação, o que impediu a documentação fotogrática, por falta de

1) Departamento de Bioquímica, Universidade Federal do Paraná. Caixa Postal 19()46. $81531-970$ Curitiba, Paraná. Brasil. 


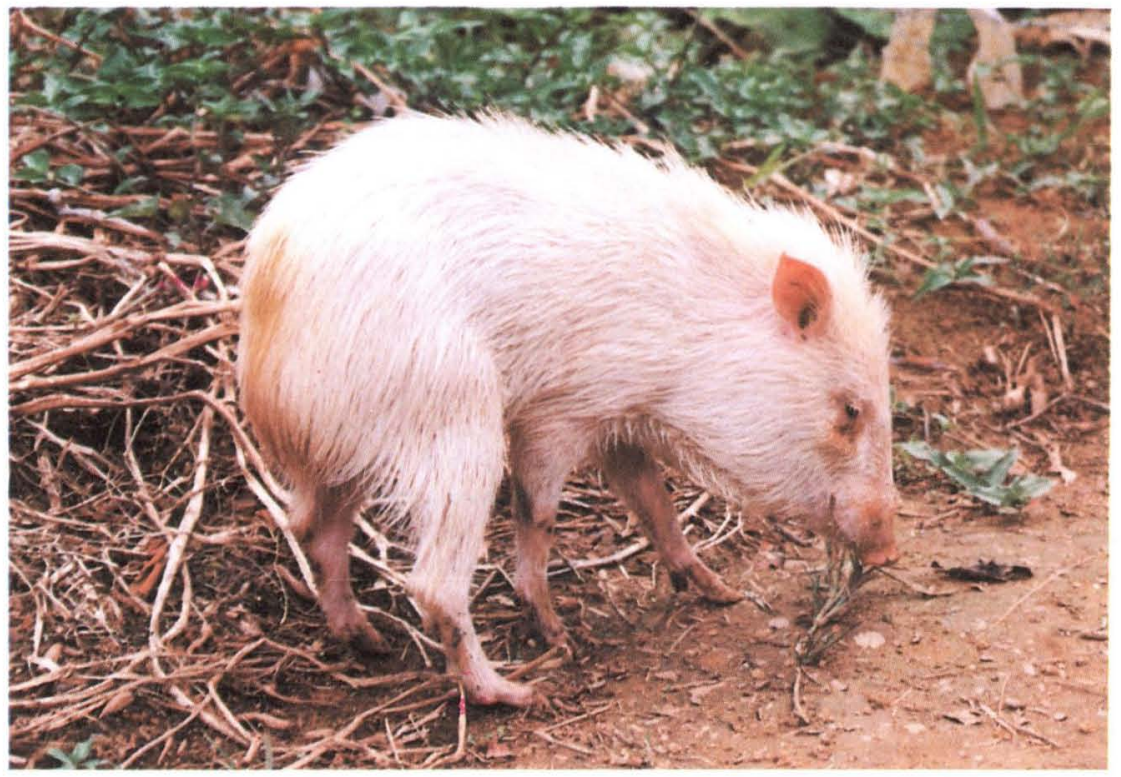

Fig. 1. Exemplar albino de cateto (Taysddu tajacu L.)

uma teleobjetiva (VEIGA \& PARDO 1990). Segundo informações de moradores das margens do Rio Negro (Amazônia), foram observados indivíduos totalmente brancos entre os vários grupos de macacos prego (Cebus apella Linnaeus, 1758) que ocorrem na região (ALMEIDA com. pes.). O mesmo pesquisador comunica um caso de forte rejeição sofrida por uma cutia albina (Dasiprocta sp.), após ser introduzida num grupo de animais normais, no zoológico de Recife, o que culminou com sua morte em poucos dias. BAYMA (1992) relata as ocorrências de uma girafa albina (Giraffa camelopardalis Gray, 1821) no Parque Tarangire, na Tanzânia, e de alguns crocodilos (Alligator mississipiensis Gray, 1831) dos pântanos de Nova Orleans, US, que possuem a pele branca e os olhos azuis. Recentemente, VEIGA \& TeIXEIRA (1993) relataram a ocorrência de um caso de albinismo em Bothrops alternatus Bibron \& Duméril, 1854, no Rio Grande do Sul.

O presente trabalho descreve a ocorrência de um caso de albinismo em cateto (Tayassu tajacu) nas matas da Serra do Mar.

\section{DESCRIC̣ÃO DA OCORRÊNCIA}

Não foi encontrada na bibliografia disponível referências à ocorrência de albinismo nesta espécie de animal. É bem conhecido o fato de que os animais albinos, principalmente quando jovens, possuem dificuldade para se dissimularem no meio ambiente, tornando-se alvos fáceis para seus predadores naturais.

O exemplar albino de Tayassu tajacu, descrito aqui, foi capturado na Serra do Mar, na Colônia Castelhanos, município de São José dos Pinhais, em setembro 
de 1992, com bem pouco tempo de vida e conseguiu, com a ajuda de moradores da região, João e Sofia Lamberg, chegar à fase adulta em perfeitas condições de saúde. Quando capturado ainda possuía parte do cordão umbilical.

Foi alimentado, até os seis meses de idade, com leite de vaca. Primeiramente em mamadeira e logo depois em vasilha especialmente separada para tal. Após os seis meses já foi oferecida alimentação sólida, composta de milho, mandioca e farelo, com leite. Atualmente recebe a ração balanceada utilizada para alimentação dos porcos domésticos criados na propriedade.

O animal em questão foi capturado por Dejair de Lima Claudino, que o vendeu ao casal Lamberg, já citado. Tem a pelagem totalmente branca, assim como é branca sua pele. Os olhos são azulados, pesou cerca de 15 quilos, não exatamente, uma vez que esta operação foi realizada utilizando-se uma balança de pouca precisão. Mediu $70 \mathrm{~cm}$ de comprimento total: a cabeça mediu 28 e o resto do corpo $42 \mathrm{~cm}$. Sua altura na garupa mediu $47 \mathrm{~cm}$ e na paleta $38 \mathrm{~cm}$. A circunferência do abdômen mediu $60 \mathrm{~cm}$ e do tórax $61 \mathrm{~cm}$. Possue orelhas pequenas e eretas. As mãos tem quatro unhas e as traseiras somente três.

Existem fortes indícios de que as declarações de Irineu Padilha e Paulo Padilha de Oliveira, de que teriam avistado na mata da região, outro animal da mesma espécie também portador de albinismo, sejam verdadeiras.

\section{REFERÊNCIAS BIBLIOGRÁFICAS}

Bayma, S. 1992. O alto preço da beleza branca. Os Caminhos da Terra 1 (8): 34-40.

Beadle, G.W. 1945. Biochemical Genetics. Chem. Rev. 37: 15-96.

CAVAlli-SForzA, L.L. \& W.F. BODNER. 1971. The genetics of human populations. San Francisco, W.H. Freeman \& Co. Ed., 965p.

Falls, H.F. 1953. Albinism. Trans. Am. Acad. Ophtal. \& Otolaringol., p. 324-331.

HarRis, H. 1962. Biochemical Genetics. Cambridge, Cambridge Univ. Press, $554 \mathrm{p}$.

Karlson, P.; W. Gerok \& W. Groos. 1982. Patobioquímica. Rio de Janeiro, Ed. Guanabara-Koogan, 32lp.

LERNER, A.B. \& T.B. FITZPATRICK. 1950. Biochemistry of Melanin Formation. Physiol. Rev. 30: 91-126.

MAYS, L.L. 1981. Genetics: a molecular approach. New York., MacMillan Publ.Co., 639p.

VeigA, L.A. \& E. PARDo. 1990. Occorrência de um caso de albinismo em sabiá laranjeira. Arq. Biol. Tecnol. 33: 329-333.

Veiga, L.A. \& A. Teixeira. 1993. Albinismo em Bothrops alternatus Dm. \& Bibr., 1854 (Ophidia, Viperidae). Arq. Biol. Tecnol. 36: 521-524.

WALTER, H.E. 1938. Genetics: an introduction of the study of heredity. New York, Mac-Millan Publ. Co., 412p.

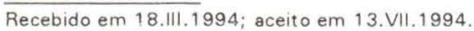

